Proceedings of the 2013 Winter Simulation Conference

R. Pasupathy, S.-H. Kim, A. Tolk, R. Hill, and M. E. Kuhl, eds

\title{
EVALUATION OF DIFFERENT BERTHING SCENARIOS IN SHAHID RAJAEE CONTAINER TERMINAL USING DISCRETE-EVENT SIMULATION
}

\author{
Hamidreza Eskandari \\ School of Industrial Engineering \\ Advanced Simulation Lab \\ Tarbiat Modares University \\ Tehran 14115, Iran \\ Mohammad Amin Rahaee \\ Industrial and Systems Engineering \\ Tarbiat Modares University \\ Tehran, PO Box 14115-143, Iran \\ Erfan Hasannayebi \\ Industrial and Systems Engineering \\ Tarbiat Modares University \\ Tehran, PO Box 14115-143, Iran \\ Mehrdad Memarpour \\ Industrial and Systems Engineering \\ Tarbiat Modares University \\ Tehran, PO Box 14115-143, Iran \\ Seyed Ashkan Malek \\ M.S. Industrial and Operations Engineering \\ University of Michigan \\ Ann Arbor MI 48109
}

\begin{abstract}
In this paper a simulation model is developed for evaluation of different berthing scenarios in Shahid Rajaee Container Terminal. Model is trying to handle Berth Allocation and Quay-Crane Assignment Problems simultaneously for more efficient solutions. Validity of developed model is examined by sensitivity analysis on model parameters and after that three berthing scenarios has been put to test in model and obtained results suggests that "Length Based Allocation" berthing scenario can reduce the turnaround time for vessels and also increase completed jobs by berth at a fixed time period.
\end{abstract}

\section{INTRODUCTION}

Sea transportation has made its way through today's world trading business as one of the most economic and reliable methods of transportation. In this method, vessels or transporter ships serve as the main entities of the system and they are mainly planned to work based on following orders:

- Liner Vessels: These vessels work on regulated paths with specified schedules.

- Feeder Vessels: These vessels get hired for doing jobs in transportation system and will be planned and scheduled for that job exclusively.

A different approach of classifying transporter vessels relies on their physical properties. One particular type of vessels in this ordering is called "Container Vessels" which have the ability of carrying cargos 
of different sizes, weight or shape. These vessels generally use standard steel or aluminum boxes called "Containers" as packaging mode for handling cargo. Packing cargos in standard containers, has the advantage of safekeeping as well as acceleration in Loading and Unloading process, weather on the transporter vessels or on the other transportation mediums such as trains or trucks.

As a result of using containers as standard units of cargo, ports dealing with container vessels are required to be equipped with appropriate facilities for handling container operations. These facilities generally include Quay-Cranes for loading and unloading containers into or from transporter vessels, YardTrailers for carrying containers from berths to storing locations known as yard and Yard-Cranes for unloading containers from Yard-Trailers and loading on other types of transporters. Ports with such facilities are characterized as "Container Terminals" and they could be considered as hubs for transshipment of containerized cargo from vessel to vessel or from vessel to other transportation modes (Q. Zeng and Z. Yang 2008).

First we briefly describe the case study used in this paper. Then the problem discussing is introduced and different types of problem are described. The description of modeling different components of model is presented in section 4 . The results of the simulation and consequent analyzes are presented in section 5 followed by conclusion in the section 6 .

\subsection{Case Study}

The Shahid Rajaee port is located at a distance of 1500 kilometers from Tehran, the capital city of Iran and there is a 23 kilometer distance between this port and Persian Gulf. This port connects to more than 80 ports worldwide and the highest rate of cargo transit through the country and towards the Central Asia passes through this port, and it is considered as the most active container terminal in the country. Putting this information into perspective, it can be concluded that this terminal plays a vital role in trading between Iran and other countries and has a substantial effect on the economy of the country.

All types of Liner and Feeder ships are provided with services in the container terminal of Shahid Rajaee port and 21 shipping channel of Liners are active there. The statistics related to container loading and unloading indicate that the Shahid Rajaee port is the only port in Iran connected to the container transport information network, and by considering the importance of container transportation in international transit, the crucial role of this port in north-south corridor becomes more clear.

The terminal number 1 of Shahid Rajaee port consists of 850 meters of berths with depth of 17 meters and 70 hectare of yard, and is able to accept even 7 th generation container ships. The current capacity of the port for transportation is about 2 million TEU per day. This capacity is not able to meet all the incoming demands considering the remarkable growth of container operations, and consequently, the container vessels have long stop time there which is the underlying problem for the port performance.

There are two approaches for tackling this gap. First approach is efficient planning and optimizing operations of current equipment and facilities, and the second the expansion of infrastructure. But increasing container capacity by expansion projects appears to be difficult for environmental, financial, technical and legal reasons. (Raa et al. 2011)

So a short term treatment for this issue is efficient planning of resources to gain the best possible. Also in Shahid Rajaee port a new terminal is going to be constructed including 2050 meters of berths with depth of 16 meters and 140 hectare of yard for resolving the problem in long term.

\section{PROBLEM STATEMENT}

The infrastructure in Shahid Rajaee container terminal includes a wave breaker that separates the sea environment from port facilities. A channel is constructed at the front of this wave breaker working as a gate for entrance and departure of transporter vessels, which is called "Reaching Channel". The width of reaching channel doesn't allow passing vessels headed towards different directions at the same time. But the vessels headed the same direction (i.e. all entering or exiting) can pass the channel with no impediment. 
Also an important restrictive factor is the level of water in reaching channel. Heavy vessels cannot pass if the level of water in channel is low since dredging in this area has been done to a specific level.

If mentioned conditions prevented entrance of vessels, they will wait for favorable conditions at a location called "Anchorage". The transportation of viable vessels for passing the reaching channel to berths will be done by tug boats and only can be done if the required number of tug boats for carrying the vessel is available.

Passing the channel and entering the port, there are 7 discrete berths available to be seized by vessels to unload/load cargos with different lengths. Arriving vessels, choose their berthing location according to a known berthing strategy. This allocation in optimal situation must be done in such a way that maximizes the utilization of berth. This performance measure can be calculated as stated in equation (1), where $L_{i}$ is the length of the $i^{\text {th }}$ vessel and $P_{i}$ is its time spent in berth, $L$ the total length of berths in port and $T$ the total working period of port:

$$
\text { Berth Utilization }=\frac{\sum_{i=1}^{n} L_{i} \cdot P_{i}}{L \cdot T}
$$

After berthing, the operation of unloading or/and loading of containers will be carried out using available Quay-Cranes, and after that vessels will be prepared for departure.

Protocol of departure for vessels is similar to their arrival, hence the status of reaching channel will be checked once again. Approximately these are the main steps of Berth Operations in container terminals.

Operations in container terminals falls under 4 main categories: Berth Operations, Crane Operations, Yard Operations and Gate Operations.

Berth Operations is the most important category amongst others because it concerns with operations directly on vessels and they are the main stocks of transportation companies in shipping business and decreasing the turnaround time of them can be a valuable marketing edge for any container terminal. So every improvement in this section that leads to saving time or reducing handling costs is highly encouraged by transportation companies (Zeng and Yang 2008).

As described above, main operations on seaside are the Berth Allocation and Quay-Crane Assignment Problems. Also since the solution of Berth Allocation Problem creates the essential input of Quay-Crane Assignment Problem, it's beneficial that these problems be integrated and solved simultaneously so the system doesn't experience any bottlenecks. Because without knowing the exact plan of berths allocation, assignment of Quay-Cranes is not possible due to lack of information about the position of vessels and possible assignments of cranes and without knowing the assignment plan of cranes, allocation of berths cannot be done due to lack of information about service time of each vessel in berths.

\subsection{Conceptual Model}

In this section, we'll try to capture the logical procedure behind the problem into the form of some routine steps which is called "Conceptual Model". It was stated that every vessel arriving the port, will be carried by appropriate number of tug boats only if the status of the reaching channel is suitable. This suitability is characterized as the channel not being seized by returning vessels from the berth location or simply being free of use, also the level of water being in proportion with the weight of the arriving vessel. The depth or the level of water is an unmodifiable factor and even if every other conditions for passing the vessels is satisfactory, this factor could be critical. If one of these conditions were not satisfied, the vessel won't be permitted for passing the reaching channel and it will remain in anchorage until the conditions turn to its favor. It is notable that the set of vessels waiting in anchorage have no attributes of an ordinary FCFS or LCFS queue (i.e. a vessel might arrive and pass the reaching channel sooner than any vessels in anchorage due to suitable conditions) and they all have the same priority towards each other for passing at any given time.

After this step, the status of berths will be checked and if no berth with equal or greater length than the length of the arriving vessel was available, it will stay in anchorage. Otherwise the needed number of 
tug boats will be seized for transporting the vessel from anchorage to berths. In berth, unloading and loading operation will be performed in accordance with following assumptions:

- No more than a known number of Quay-Cranes can operate on a single vessel at a particular time. This pre-determined number is called QC-Norm and is assigned to vessels according to their length and weight.

- If during the process of loading or unloading, a new Quay-Crane was released of its duty it will be seized by another vessel as long as the seized Quay-Cranes by the vessel doesn't violate the QC-Norm limitation.

After the berth operations were accomplished, the vessel will be prepared for departure. The procedure for departure is very similar to arrival. Figure 1, illustrates these steps.

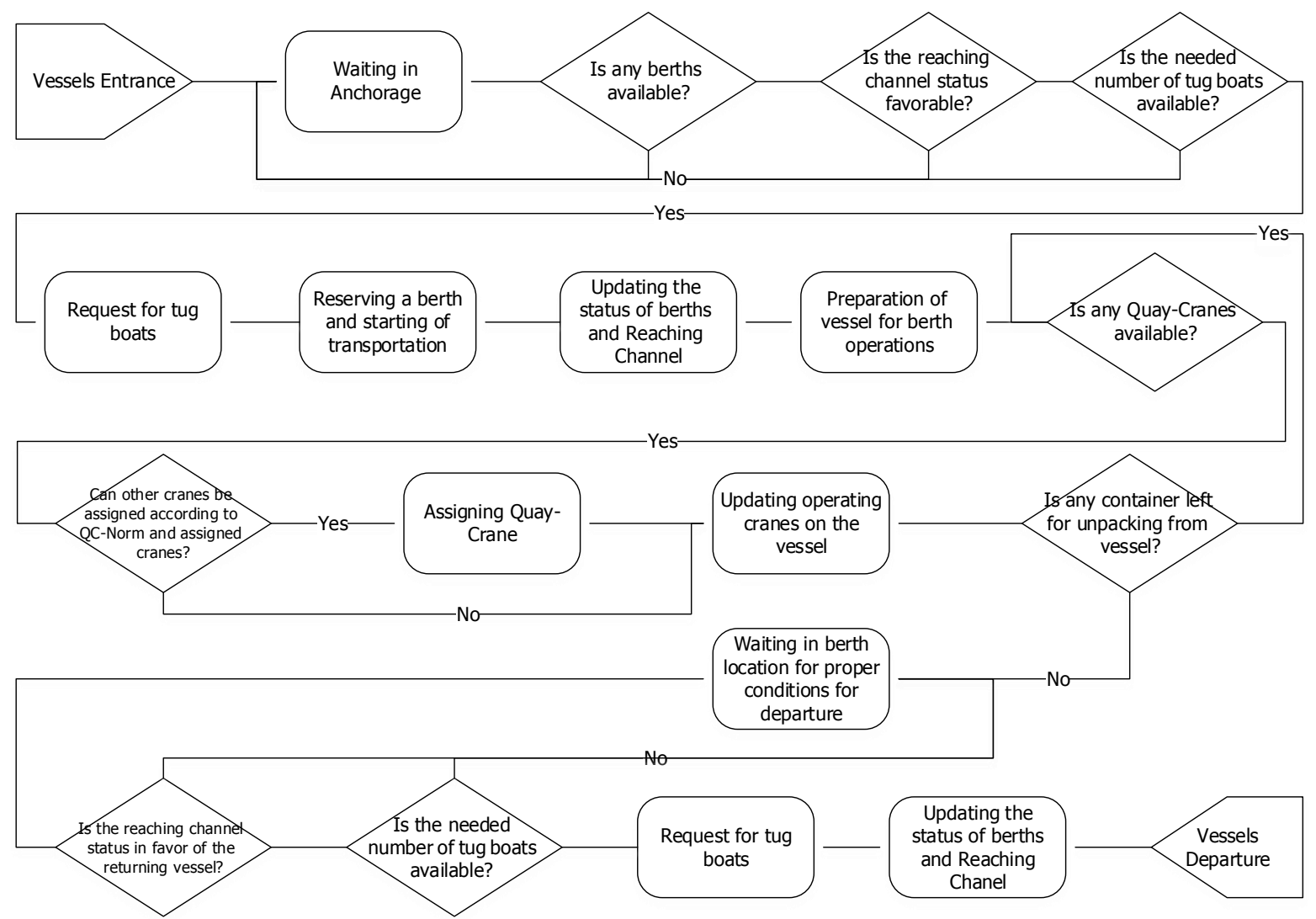

Figure 1: Conceptual Model

\subsection{Why using Simulation}

As it was stated in previous sections, we are willing to manage and plan the allocation of berths and assignment of Quay-Cranes for reducing the turnaround time of transporter vessels. But such planning requires solving an integrated type of BAP and QCAP problems. With current knowledge of computation, it's not possible to obtain optimal solutions for such problem. Nonetheless the optimal solution to the problem is not necessarily an applicable one due to operational limitations. Also trying different scenarios and finding beneficial strategies in action, is both time consuming and also costly to a great deal. In this 
situation discrete-event simulation seems to have some good advantages over the other tools. With designing a valid simulation model, answering to following questions can be obtained:

- Identifying the hold point in Berthing, Operating and Traffic of vessels in terminals

- Determining Performance Measures of terminals and effects of different scenarios on them

- Studying "Time In System" for arriving vessels and effects of different scenarios on it

So for reducing cycle time of container vessels in Shahid Rajaee port, effective planning of berth operations is required. Considering BAP and QCAP independently and combining the results at the end, ignores the interrelations that exists between these problems, hence the obtained solutions are rather obsolete in real world applications. To achieve overall efficiency and preventing each operation to become bottleneck, an integrated approach of problems using discrete-event simulation is suggested.

\section{LITERATURE REVIEW}

\subsection{Berth Allocation Problem (BAP)}

There are several papers related to berth allocation problem in the literature. In order to acquire a better understanding of these studies it is necessary to have general information about different types of BAPs. In one aspect the BAPs can be divided into two main classes; the continuous and the discrete BAP. In the discrete BAP, a dock consists of a limited number of berths and each berth can accept only one ship at a certain time, while in the continuous type of problem a ship can choose its position at any point beside the dock on condition that its length is less than the length of unused section of the berth, and consequently, it is not wrong to say that using a berth in a continuous form would lead to a better utilization in comparison with the discrete allocation.

The problems described above can be categorized according to dynamics of time in which the state of port is being considered. Based on this classification, the problem can be divided into two main types. The first one is static BAP in which all ships are assumed to enter the port simultaneously at the beginning of the operation time. In the second type, called dynamic BAP, this assumption does not exist and the ships enter gradually based on a probabilistic distribution. The overall classification is illustrated in Figure 2 .

Both discrete and continuous BAP has been studied in the literature. Lee et al.(2010) investigate the continuous BAP taking the dynamics of time into account. They are aimed to minimize the weighted summation of ship presence in the berth. A greedy randomized adaptive search procedure (GRASP) is used in order to solve the problem and obtain near optimum solutions. Imai et al.(1997) and Imai et al.(2001) consider static-discrete and dynamic-discrete BAP, respectively. In both studies, the main goals are to minimize the waiting time of ships in the port. A dynamic BAP with taking the water level limitations and multiple ships entrance into account is introduced in a study of Nishimura et al.(2001). The problem is modeled as a non-linear programming in their study.

The preemption of ships is considered in Imai et al.(2003) study. They also use a heuristic approach to solving the continuous BAP (Imai et al.2003). Lin et al.(1998) consider the BAP as a type of scheduling problem. They define the problem as a scheduling multiple jobs on one machine. A heuristic method is used in Guan and Cheung (2004) study to solve continuous BAP taking the group entrance of the ships into account. A simulation based approach is proposed in several studies such as Legato an Mazza (2001) and Henesey et al.(2004). 
Eskandari, Rahaee, Memarpour, Hasannayebi and Malek

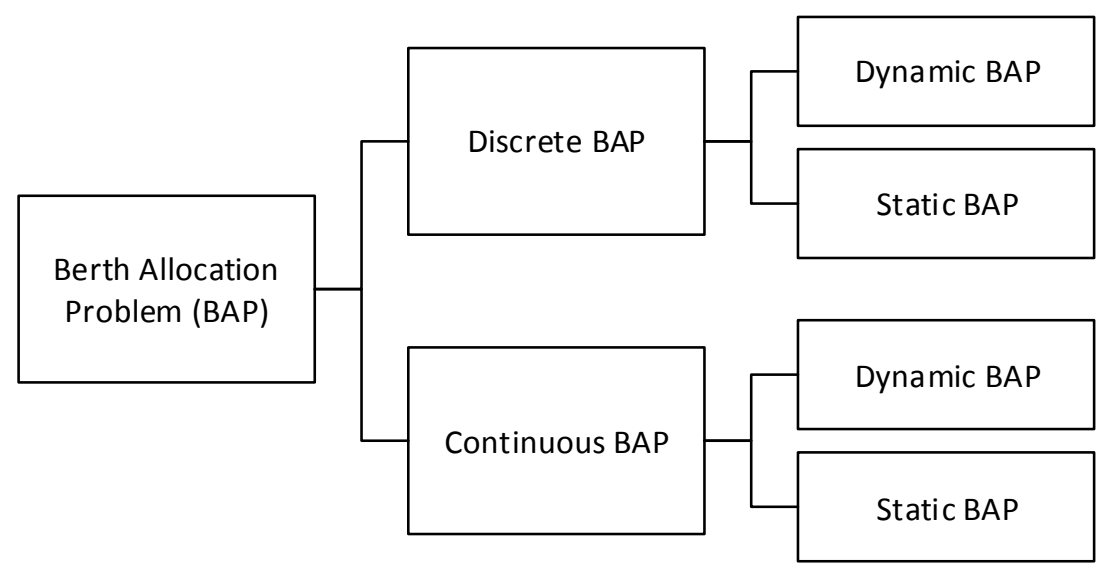

Figure 2: Berth Allocation Problem Classification

\subsection{Quay-Crane Assignment Problem (QCAP)}

The problem of allocating quay-cranes to the ships and their order of assignment to perform the loading/ unloading operations has a special importance due to its remarkable effect on the overall utilization of the port. The main objective in this problem is to allocate quay-cranes to schedule their operations in a way that the total time of loading/unloading process reaches its minimum.

Legato and Trunfio (2008) propose integer programming to model the QCAP. In the case of probabilistic loading/unloading process time they use simulation based optimization. A simulated annealing and an adaptive balanced explorative/exploitative search are utilized in order to perform the optimization operation.

The types of quay-cranes are categorized as rail-mounted gantry cranes and rubber-tired gantry cranes. For the first type the loading/unloading procedure on different ships can be performed through moving the crane. In order to carry out the loading/unloading operations there is a certain area used as a buffer to keep the containers there. The transportation process of containers by quay-cranes is illustrated in Figure 3.

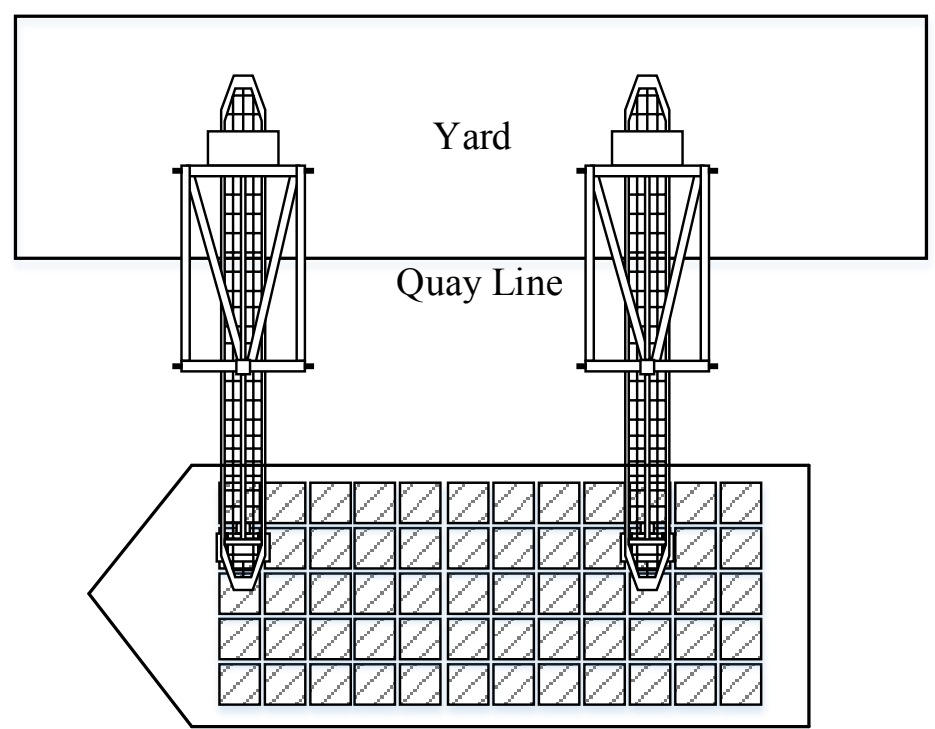

Figure 3: Transportation process of containers by Quay-Cranes 


\subsection{Integration of Berth Allocation Problem and Quay-Crane Assignment Problem}

Some integration approaches were proposed in the literature. Oguz et al. (2004), Meisel and Bierwirth (2006, 2009), Hendriks et al. (2008), Giallombardo et al. (2008) and Liang et al. (2008) proposed a deep integration of BAP and QCAP (Bierwirth and Meisel, 2010).

Deep integration is simply combining sub-problems to form a partial monolithic problem formulation which on some levels can absorb the interrelations between them.

\section{MODELING DESCRIPTION}

The proposed model merges dynamic case of BAP and QCAP. It considers stochastic arrival times for vessels and also takes into account the effects of using tug boats for transporting vessels inside port and the weather conditions constraints which is an advantage over the existing models in literature.

\subsection{Modeling Anchorage Location}

After arrival of vessels, as stated previously they will stay in anchorage until the conditions for entrance meet. In simulation model, structure in Figure 4 is used for simulating the entrance of different classes of vessels according to data collected from Shahid Rajaee port.

Implementing arrival of different types of vessels as described in previous sections, is done according to historical data with structure illustrated in Figure 5.

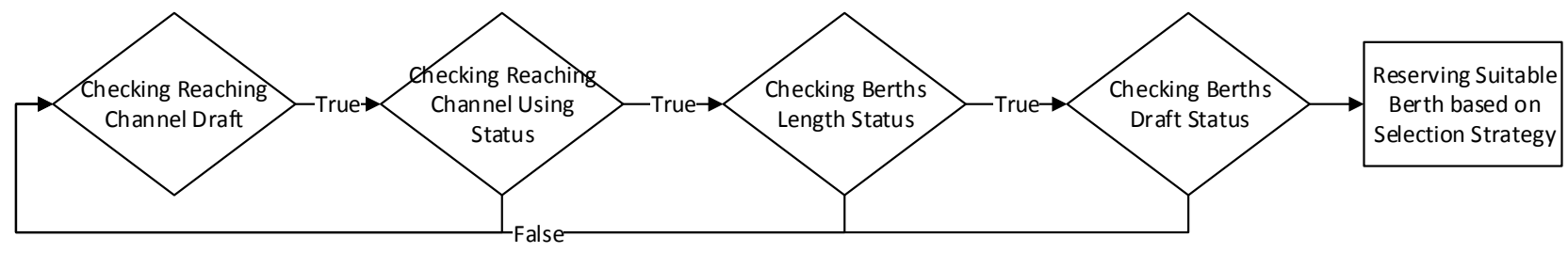

Figure 4: Vessels Entrance Structure

\subsection{Modeling Tug Boats Operation}

After assigning the appropriate berth to the ship three main conditions should be assessed in order to give permission to the ship for moving. This movement is performed by one or two tug boats (it depends upon the length of the ship). The first condition is availability of tug boats. A ship is not able to move without the tug boats it needs. Another condition is defined by the depth of the reaching channel or, in other word, the height of the water level. If the level of water is not as high as needed for the ship, ship cannot continue moving and will wait until the level become suitable. The last condition is that when a ship requests for tug boats in order to enter the berth, the number of ships which are ready for leaving the berth should be zero. This condition means that ships leaving the berth have higher priority to request tug boats and occupy reaching channel over the entering ships.

In order to model this part of system, first tug boats are created. It should be mentioned that the creation process is done once as one of the initial events of model. In this model some vessels needs more than one tug boat in order to move through the channel. Therefore tug boats are created as entities forming a queue in their station. In the next stage a ship takes needed number of tug boats from the queue and start moving subject to the satisfaction of all mentioned conditions. 


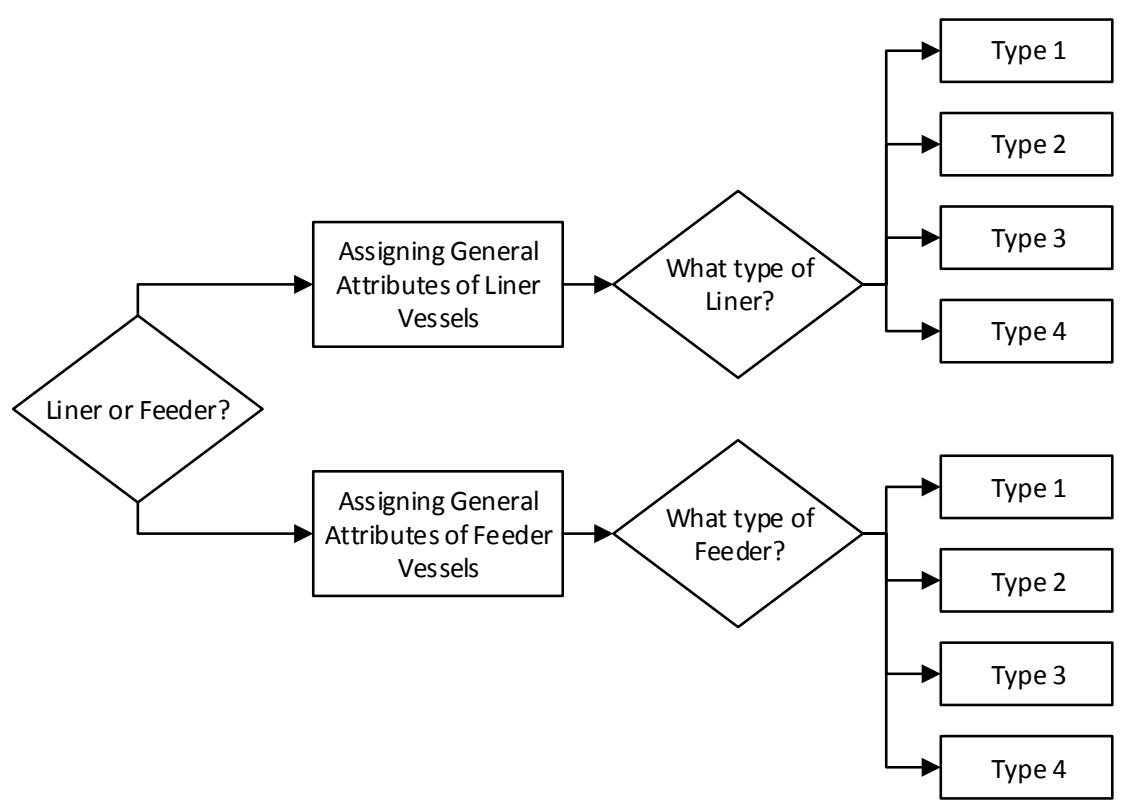

Figure 5: Distinguishing different types of arriving vessels

\subsection{Modeling Unloading/Loading Process}

After arrival of vessel to the reserved berth, unloading the available containers on vessel will be carried out. This task will be accomplished by Quay-Cranes available in berths. Logic behind assignment of Quay-Cranes was covered in previous sections in detail. For imitating such procedure, a recursive structure is implemented in model. This structure will break only if no more containers were available on vessel hence the loading/unloading process is finish. The steps are as follows:

1. If the number of containers available on vessel $\left(C_{N}\right)$ is positive, go to step 2 and go to step 7 otherwise.

2. If the number of working Quay-Cranes on the vessel is less than its QC-Norm and at least one Quay-Crane is available go to step 3 and go to step 4 otherwise.

3. Assign a capacity of $\min \{(Q C N o r m-Q C S e i z e d), A v a i l a b l e Q C\}$ from Quay-Cranes to the current vessel, where "QCNorm" is the QC-Norm attribute of vessel, "QCSeized" indicates the number of currently assigned Quay-Cranes on the vessel and "AvailableQC" indicating the idle QuayCranes.

4. Update the remained containers on vessel using Unload Rate of Quay-Cranes and the number of currently working Quay-Cranes on the vessel:

$$
C_{N}=\max \left\{\left[C_{N-1}-(U R \times \text { QCSeized })\right], 0\right\}
$$

Where, " $C_{N}$ " is updated number of containers available on vessel, " $C_{N-1}$ " is the number of containers before current iteration starts and " $U R$ " indicates Quay-Cranes Unloading Rate per hour.

5. Wait for $\left(\frac{C_{N}-C_{N-1}}{U R}\right)$ hours, as simulating the time consumption of loading/unloading operation.

6. Return to step 1.

7. Check conditions of departure for vessel. 
The schematic representation of this procedure is represented in Figure 7.

\subsection{Modeling Water Level}

Structure in Figure 7 is implemented in model for simulating the behavior of water level. A dataset containing data records of water level in a period of time is stored as a spreadsheet format. A dummy procedure reads that data every 5 minutes (since the dataset was collected accordingly).

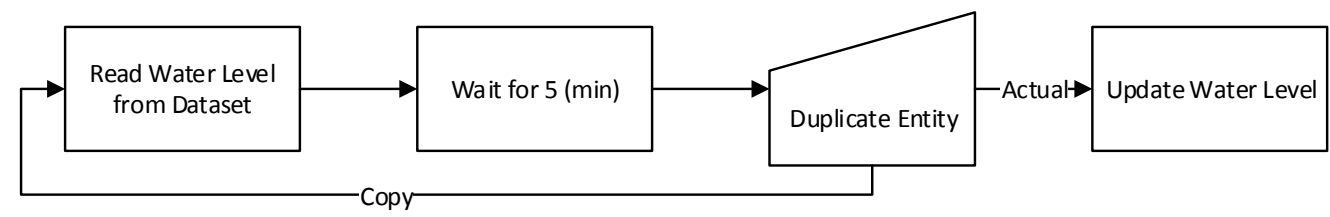

Figure 6: Dummy procedure for simulation of water level

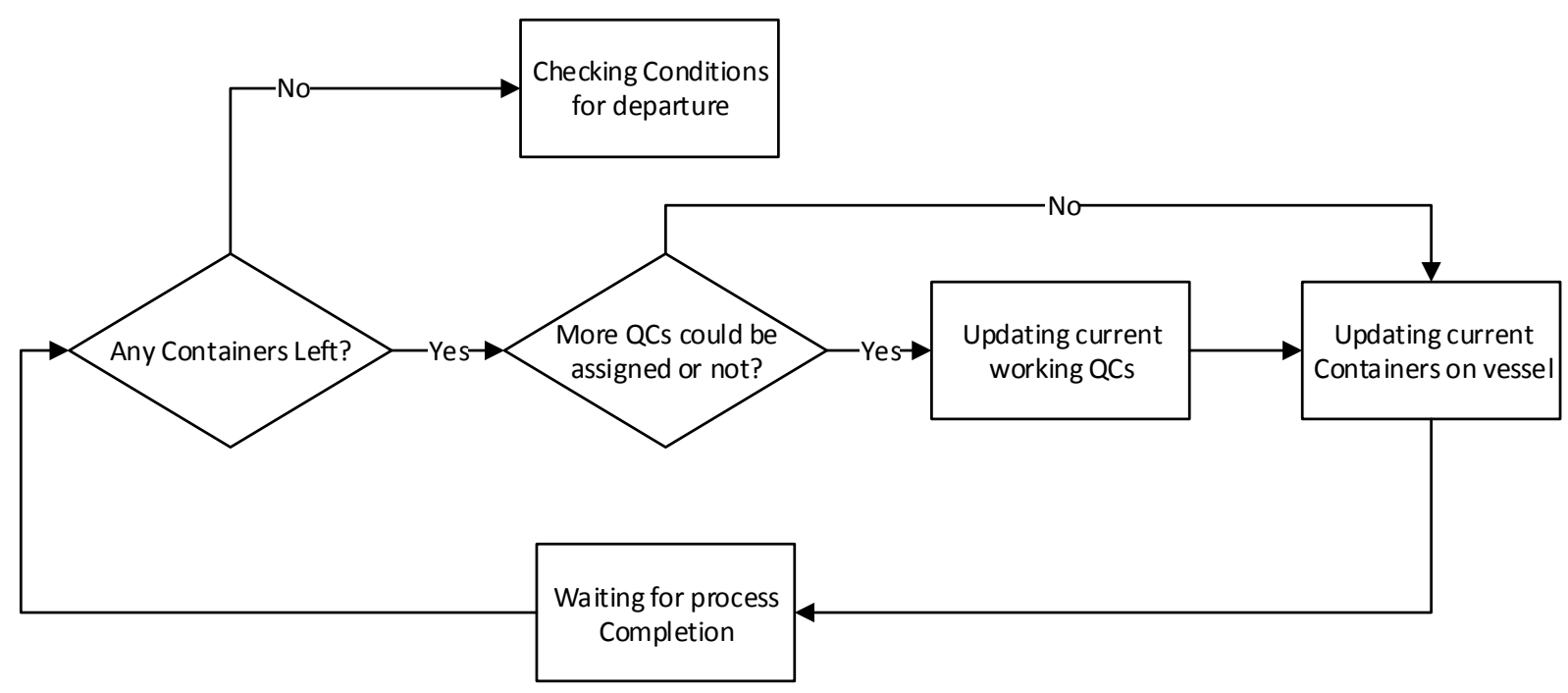

Figure 7: Unloading/Loading Process

\section{RESULTS}

It was stated every scenario reducing turnaround times of vessels in port is a crucial factor, for this matter eliminating non-value added times has the highest priority. Also it is obvious, that eliminating the causes of delay in berth operations will yield more completed jobs in a fixed time period. So "Total waiting time in anchorage" and "Number of jobs done" could be two consistent performance measure for evaluation of different scenarios.

\subsection{Validation}

Before evaluation of different scenarios using designed simulation model, some manipulations were made in parameters for examining validity of model. These manipulations were made in such a way which their effects in model results can be inferred logically.

First, we observe the effect of increasing the number of tug boats on waiting time in anchorage. As it was stated availability of required number of tug boats for carrying vessels to berths is a restrictive factor. 
So it is logical that this increase in capacity would have the result of decreasing waiting times in anchorage. Sensitivity analysis on number of tug boats were made and Figure 8 shows the results. This figure shows that this change in model, caused decreasing in both waiting time for entrance and departure.

Equipping berths with more Quay-Cranes, should reduce the waiting times in system since more cranes can work on vessels and according to assumptions in "Modelling Load/Unload Process" section process time will be reduced so turnaround time or "Total Time in System" for vessels will decrease. The results obtained by simulation model in Figure 9 is a proof of this hypothesis as well. But it is notable this expansion in capacity reaches to an asymptotic value and after that it doesn't affect the "Total waiting time in anchorage" and other components of system become critical like the vessels arrival order.

Besides increasing the capacity of Quay-Cranes, increasing Unload/Load Rate of cranes should have similar results on model as the increase in capacity had. Sensitivity analysis on this parameter confirms this idea and the results are shown in Figure 10.

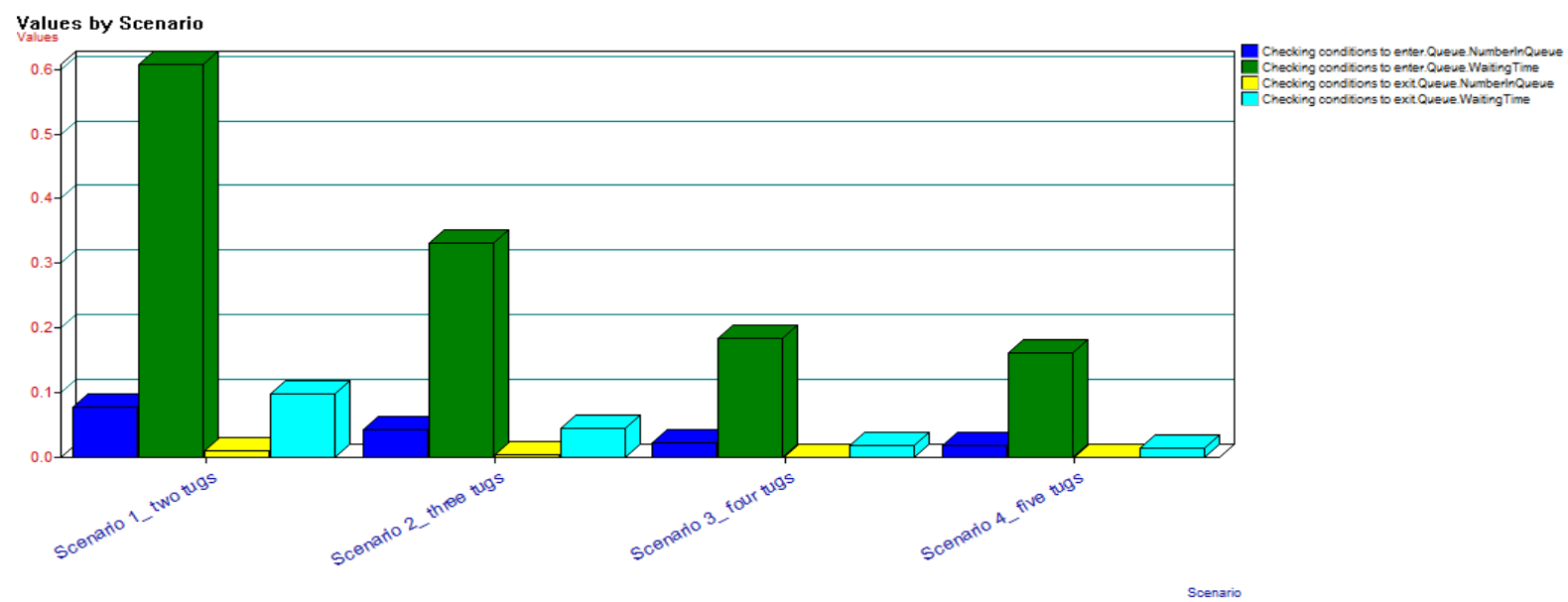

Figure 8: Effect of increasing Tug Boats capacity on Waiting Times in system

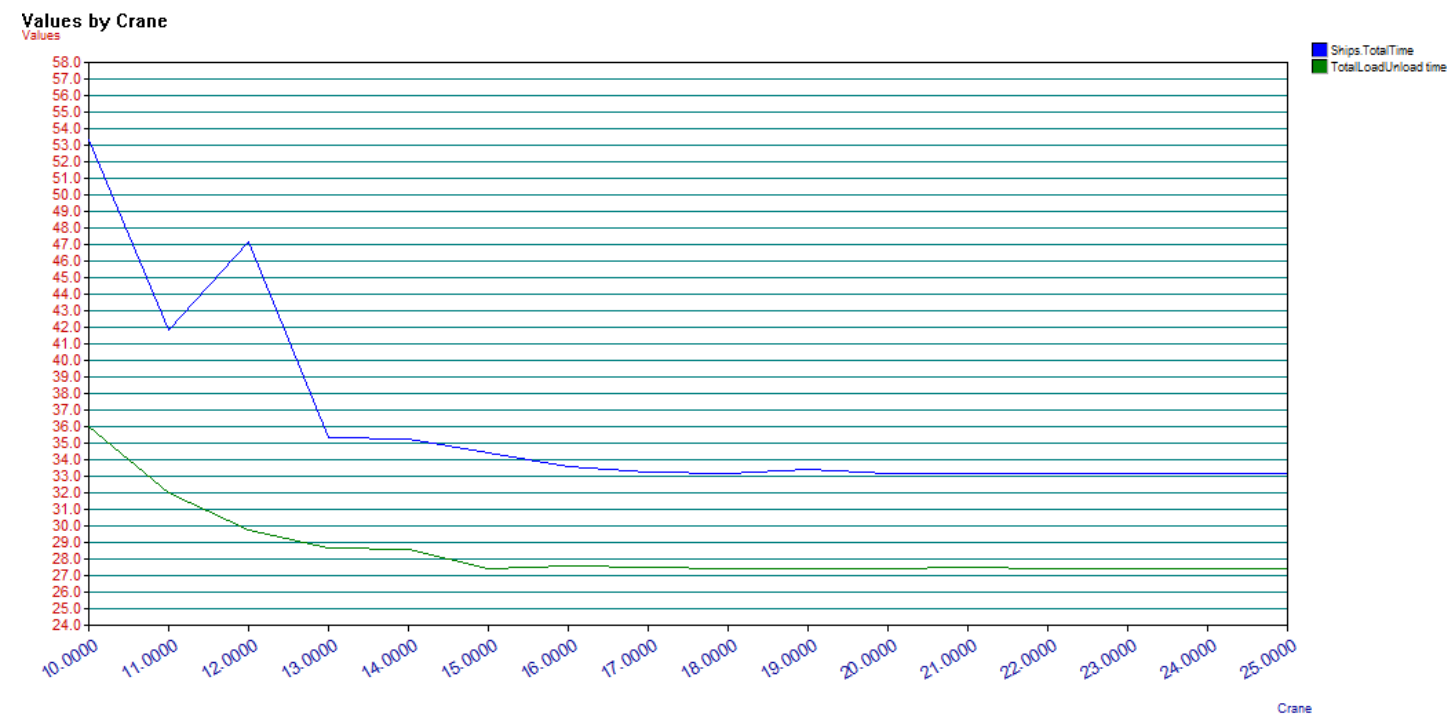

Figure 9: Effect of increasing Quay-Cranes capacity on Waiting Times in system 
Eskandari, Rahaee, Memarpour, Hasannayebi and Malek

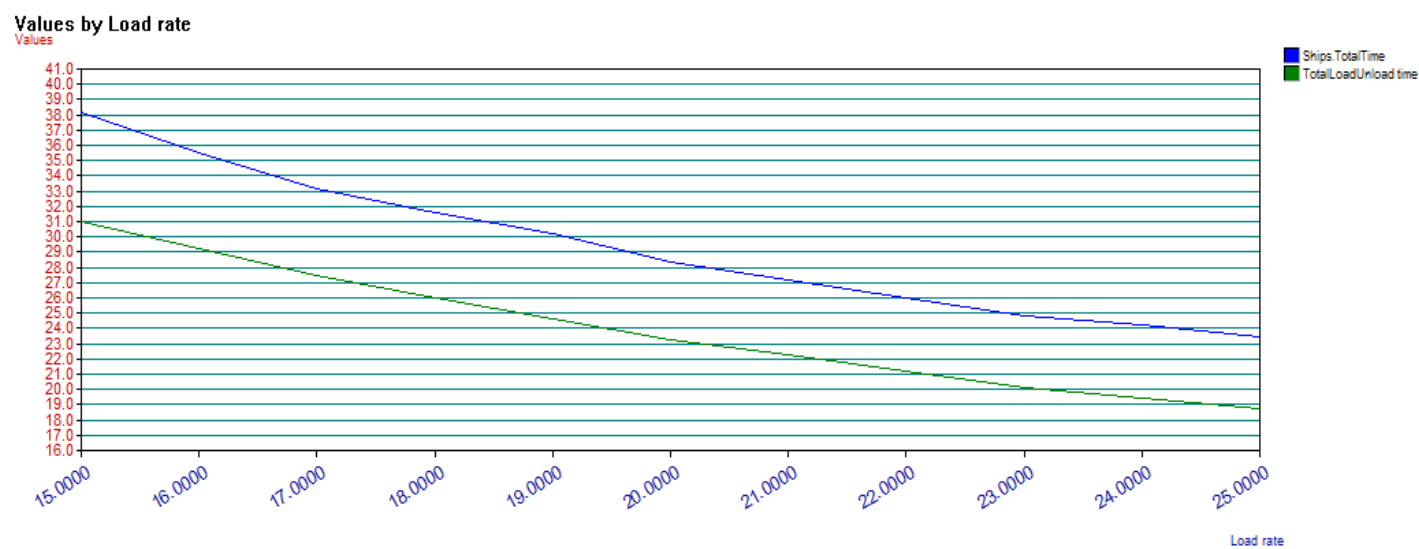

Figure 10: Effect of increasing Load/Unload Rate of Quay-Cranes on Waiting Times in system

\subsection{Scenario Evaluation}

Following scenarios were examined by simulation model:

1. Random Allocation: If only one berth is suitable for arriving vessel it will be chosen for berthing but if more than one berth was available for arriving vessel, a random allocation will be carried out.

2. Length Based Allocation: In this strategy, berth with minimum unused length amongst available berths for vessel will be chosen.

3. Draft Based Allocation: In this strategy, berth with minimum difference between water level requirement of vessel and current sea draft, amongst available berths for vessel will be chosen.

The results obtained by simulation model in Table 1 suggests the "Length Based Allocation" scenario since it improved both measures.

Two following issues are noteworthy: I) although "Total waiting time in anchorage" in first scenario is better than second or third, the factor "Number of jobs done" for it is lower than others. II) Also "Number of jobs done" for third scenario is not significantly greater than the second but "Total waiting time in anchorage" shows the advantage of second scenario over the third.

Table 1: Berthing scenarios and performance measure

\begin{tabular}{clccc}
\hline Index & \multicolumn{1}{c}{ Scenario Name } & $\begin{array}{c}\text { Number of Completed } \\
\text { Jobs }\end{array}$ & $\begin{array}{c}\text { Works In Process } \\
\text { (WIP) }\end{array}$ & $\begin{array}{c}\text { Waiting Time in } \\
\text { Anchorage }\end{array}$ \\
\hline 1 & Random Allocation & 600.200 & 4.324 & 1.921 \\
2 & Length Based Allocation & 615.900 & 4.452 & 2.075 \\
3 & Draft Based Allocation & 616.100 & 4.555 & 2.516 \\
\hline
\end{tabular}

\section{CONCLUSION}

Since most efforts in improving berth operations in container terminals, only focused on Berth Allocation Problem or Quay-Crane Assignment Problem individually, this paper tried to put forward a new approach for considering both problems simultaneously with tug boats availability and weather conditions con- 
straints. Main reason for this integration is preventing the instability in system which will occur if both sub-systems are working efficient individually but inefficient toward each other.

As a complementary strategy adding more Quay-Cranes could also reduce non-value added times in system but this strategy loses its affection at a given capacity of this resource.

Simulation model suggests the "Length Based Allocation" in comparison with "Random Allocation" and "Draft Based Allocation" scenarios since it improved non-value added times and also completed jobs by system significantly.

Following areas are open for further research:

- Using simulation based optimization for generating hybrid scenarios with higher productivity

- Adding Quay-Crane Scheduling Problem (QCSP) to integrated model

- Adding more details about yard operations in model and reformulation of problem

\section{REFERENCE}

Zeng, Q., Yang, Z., 2008. Integrating simulation and optimization to schedule loading operations in container terminals, Computers \& Operations Research ,36,1935-1944.

Guan, Y., Cheung, R., 2004. The berth allocation problem: models and solution methods. OR Spectrum, 26 (1), 75-92.

Henesey, L., Davidsson, P., Persson, J. 2004.Using simulation in evaluating berth allocation at a container terminal .In Proceedings for the $3^{\text {rd }}$ International Conference on Computer Applications and Information Technology in the Maritime Industries (COMPIT 04). pp. 61-72.

Imai, A., Nagaiwa, K., Chan, W., 1997. Efficient planning of berth allocation for container terminals in Asia. Journal of Advanced Transportation, 31 (1), 75-94.

Raa, B., Dullaert, W., Van Schaeren, R., 2011, An enriched model for the integrated berth allocation and quay crane assignment problem, Expert Systems with Application, 38, 14136-14147.

Bierwirth, C., Meisel, F., 2010, A survey of berth allocation and quay crane scheduling problems in container terminals, European Journal of Operational Research, 202, 615-627.

Imai, A., Nagaiwa, K., Chan, W. 1997. Efficient planning of berth allocation for container terminals in Asia. Journal of Advanced Transportation, 31 (1), 75-94.

Imai, A., Nishimura, E., Papadimitriou, S. 2001.The dynamic berth allocation problem for a container port. Transportation Research Part B, 35 (4), 401-417.

Imai, A., Nishimura, E., Papadimitriou, S. 2003. Berth allocation with service priority. Transportation Research Part B 37 (5), 437-457.

Legato, P., Mazza, R., 2001. Berth planning and resources optimization at a container terminal via discrete event simulation. European Journal of Operational Research, 133 (3), 537-547.

Legato, P., and Trunfio, R. 2008. Simulation-based optimization for the quay crane scheduling Problem. In Proceedings of the 2008 Winter Simulation Conference.

Lee, D.H., Chen, J., and Cao, X. 2010 .The continuous Berth Allocation Problem: A Greedy Randomized Adaptive Search Solution. Transportation Research Part E 46, 1017-1029.

Lin, C., Cai, X., Lee, C. 1998.Scheduling with multiple-job-on-one-processor pattern. IIE Transactions 30 (5), 433-445.

Nishimura, E., Imai, A., Papadimitriou, S. 2001. Berth allocation planning in the public berth system by genetic algorithms. European Journal of Operational Research, 131 (2), pp. 282-292.

Pidgeon, E.D. 2008, Modeling The Effects Of A Transportation Security Incident Upon The Marine Transportation System. Master's Thesis, Naval Postgraduate School.

Guan, Y., Cheung, R., 2004. The berth allocation problem: models and solution methods. OR Spectrum, $26(1), 75-92$.

Portal of Shahid Rajaee Container Terminals 2012. "Shahid Rajaee Complex Portal” Accessed January 18. http://shahidrajaeeport.pmo.ir/en/home. 


\section{AUTHOR BIOGRAPHIES}

HAMIDREZA ESKANDARI is an Assistant Professor of Industrial Engineering and director of Advanced Simulation Lab at the Tarbiat Modares University, Tehran, Iran. He received his Bachelor's degree in Electrical Engineering from the University of Tehran (1998), his Master's degree in SocioEconomic Systems Engineering from the Iran University of Science and Technology (2001) and his Ph.D. in Industrial Engineering from the University of Central Florida (2006). His research interests include Simulation Modeling and Analysis, Simulation Optimization, and Evolutionary Multi-objective Optimization. His email address is eskandari@modares.ac.ir.

MOHAMMAD AMIN RAHAEE is M.Sc. student in Industrial Engineering at Tarbiat Modares University, Iran. His research interests are in areas of Meta-Heuristic Algorithms, Mathematical Programming, Discrete-Event Simulation and Simulation based optimization. He can be reached at amin.rahaee@modares.ac.ir.

MEHRDAD MEMARPOUR is M.Sc. student in Industrial Engineering at Tarbiat Modares University, Iran. He graduated as B.Sc. from Tehran University, Iran in 2012. His research interests are in areas of Logistics, Customer Lifetime Value, Supply-Chain Management, Mathematical Programming. He can be reached atm.memarpour@modares.ac.ir.

ERFAN HASSAN NAYEBI is PhD student in Industrial Engineering at Tarbiat Modares University, Iran. Received his M.Sc. for industrial engineering at Sharif university of Technology in 2012. During his career at SIMARON he has contributed in a wide variety of simulation-based optimization studies for railway companies. His research interests are in the area of mathematical programming, simulation and meta-heuristic algorithm. He can be reached at er_nayebi@yahoo.com.

SEYED ASHKAN MALEK is a Product Manager in Hyper Office. He has received his Master of Science in Industrial and Operations Engineering from the University of Michigan, Ann Arbor. His Bachelor's was also in the field of Industrial Engineering awarded from Sharif University of Technology in Tehran. He has done a lot of research and conducted a number of projects in discrete event simulation as parts of simulation courses taken both in undergraduate and graduate studies. He can be reached at ashkanm@umich.edu. 